\title{
Cardiovascular Risk Factors among Malaysian Diabetic Patients \\ ORIGINAL
}

\section{Abstract}

Background: Diabetes mellitus is a major health problem that can lead to micovascular and macrovascular complications mainly cardiovascular diseases which is an important cause of morbidity and mortality among diabetic patients.

Aims: The aim of this research is to discover the common health problems among Malaysian diabetic patients and to identify the predictors for cardiovascular diseases among those patients.

Study Design: Cross sectional study.

Methods: A retrospective review analysis of the records of diabetic patients who attended Hospital Universiti Sains Malaysia in 2010 was conducted. Two hundred and forty five diabetic patients' records were reviewed and analysed.

Results: Cardiovascular diseases were reported in 19.6\% among the diabetic patients. Those with cardiovascular disease have a longer duration of diabetes than those without cardiovascular disease $(P=0.03)$. Total cholesterol level was higher among diabetics with cardiovascular disease than in those without cardiovascular disease $(P=0.02)$. High density lipoprotein cholesterol level was lower among diabetics with cardiovascular disease $(P=0.01)$.

Conclusion: Predictors of cardiovascular disease were family history of premature cardiovascular disease, age risk, total cholesterol, low high density lipoprotein cholesterol, and duration of diabetes.
Alyaa Al-Khateeb ${ }^{1,5}$ Mohd Sapawi Mohd², Zurkurni Yusof ${ }^{3}$, Hassanain Al-Talib', Bin Alwi Zilfalil ${ }^{4,5}$

1 Faculty of Medicine, Universiti Teknologi MARA (UiTM), Sungai Buloh, Selangor, Malaysia.

2 Hospital Sultanah Nur Zahirah, Kuala Terengganu, Terengganu; Malaysia.

3 Department of Medicine, School of Medical Sciences, Universiti Sains Malaysia, Kubang Kerian, Kelantan, 16150, Malaysia.

4 Department of Pediatrics, School of Medical Sciences, Universiti Sains Malaysia, Kubang Kerian, Kelantan, 16150, Malaysia.

5 Human Genome Centre, School of Medical Sciences, Universiti Sains Malaysia, Kubang Kerian, Kelantan, 16150, Malaysia.

Contact information:

\section{Alyaa AL-Khateeb.}

M.B.Ch.B, MSc., Ph.D Medical Genetics

Address: Faculty of Medicine, Universiti Teknologi MARA (UiTM), Sungai Buloh Campus. Jalan Hospital. 47000 Sungai Buloh, Selangor, Malaysia.

Tel: +60129545014

Fax: 03-61265082.

झ alyaa_1974@yahoo.com

\section{Keywords}

Diabetes Mellitus; Low Density Lipoprotein; Malaysians; Cardiovascular Risk Factors. 


\section{Introduction}

Diabetes Mellitus (DM) is a major and a rising health problem. According to the International Diabetes Federation (IDF) Atlas, DM affected around 285 million globally in 2010 and is estimated to reach 438 million by 2030. [1] In UK, there has been an increasing in the occurance of diabetes, with an estimated overall prevalence of 4\%. [2] It was recorded that just about $20 \%$ of Asians and $17 \%$ of AfroCaribbean people who their age is over 40 years have type-2 diabetes. [3]

Diabetes is a major health problem in Malaysia and is predicted be more aggravated in the future. [4] The Second National Health and Morbidity survey could report about 3.4 million Malaysian diabetics in 2010. [5]

Diabetes care is far-off from the satisfactory targets with the majority of patients were not achieving the clinical goals at the same time the rate of complications is still so high. Serious efforts are needed to look for early diagnosis and proper management of diabetic patients, otherwise the nation will be loaded by the long-suffering diabetic subjects and their complications. [4]

Diabetes mellitus in general and specifically type2 diabetes may lead to serious long-term microvascular (diabetic retinopathy and nephropathy) and macrovascular (cardiovascular,,cerebrovascular and peripheral vascular diseases) complications which are responsible for disease morbidity, mortality and hospital admission. [6]

Cardiovascular disease (CVD) is a condition that includes diseases affecting the heart and its arterial system, it is currently the major cause of hospitalizations and death in the developed countries.

Data from the National Cardiovascular Disease Database (NCVD) Malaysia reported that CVD is the principal cause of death; it causes about $25 \%$ of deaths in the Ministry of Health hospitals at 2011. [7]

Rapid changes in both dietary behaviour and life styles in most Asian countries have occurred to- gether with the rapid economic growth over the last 2-3 decades. These changes mean that some diet-related chronic diseases maybe exaggerated in later adult life, possibly explaining the increased risk of coronary artery disease in south Asian populations. [8] It was demonstrated in a study by Chen and his co-authors in China where rapid urbanization has occurred, rising lipid profile parameters have become an increasing health problem, with a consequent increase in CVD risk. [9]

The National Cholesterol Education Program (NCEP) Adult Treatment Panel (ATP) III identify important factors that contribute to the development of CVD, such as smoking, hypertension, DM and family history of premature cardiovascular disease (PCVD). [10]

Cardiovascular disease is the chief cause of both morbidity and mortality among diabetic patients. [11] the risk of death due to CVD is 2 to 3 times more in diabetic patients rather than nondiabetics, CVD is contributing to the high incidence of macrovascular complications among diabetics that can lead to a significant health burden and a increase the health care cost in the community. For that reason, identification of cardiovascular risk predictors among diabetic patients is of a particular importance in order to build more effective preventive plans. [12]

The aim of this study is to look for the concomitant clinical problems of Malaysian diabetic patients (type 1and type 2 diabetics) and to identify the predictive factors for CVD among these patients.

\section{Methods}

In this study, the patient sample was based on a computer-generated list of 245 diabetic patients (inpatients and outpatients), (both type 1 and type 2 diabetics), which was obtained from the Record Unit at Hospital Universiti Sains Malaysia (HUSM). Subjects were diabetic patients who attended HUSM in 2010. The first recorded fasting blood 
sugar was regarded as a baseline reading. The first fasting lipid profile parameters recorded before starting lipid-lowering therapy were regarded as baseline values. Diabetes was diagnosed by $2-\mathrm{h}$ $P G \geq 11.1 \mathrm{mmol} / /(200 \mathrm{mg} / \mathrm{dL})$ or $F P G \geq 7.0 \mathrm{mmol} / /$ $(126 \mathrm{mg} / \mathrm{dL})$ or a patient with classic symptoms of hyperglycemia or hyperglycemic crisis with a random plasma glucose of $11.1 \mathrm{mmol} / \mathrm{L}(200 \mathrm{mg} / \mathrm{dL})$ [13]. The variables that were documented are: age, sex, ethnicity, smoking status, stroke, and presence of related clinical problems (hypertension defined as systolic blood pressure $\geq 140 \mathrm{~mm} \mathrm{Hg}$ or diastolic blood pressure $\geq 90 \mathrm{~mm} \mathrm{Hg}$ or both [14] and/ or patient's use of antihypertensive drugs); family history of PCVD was defined as age of onset of having CVD before 55 years for men and before 65 years for women among the first-degree relatives. [15] Clinical CVD was defined as a myocardial infarction i.e new Q waves or ST elevation or new $\mathrm{T}$ wave inversion persisting in more than two leads plus creatine kinase level of >400 IU/l, or a past history of percutaneous transluminal coronary angioplasty (PTCA), coronary artery bypass grafting(CABG), having angina with an ischemic resting echocardiogram, or an angiogram that reported a clinically important stenosis. The age risk was defined as men $\geq 45$ or women $\geq 55$. [16]

Before conducting the present study an ethical approval was attained from Universiti Sains Malaysia (USM) Research and Ethics Committee (Ref no 195.4(2.2).

\section{Statistical Analysis:}

All numerical data were presented as mean (SD), while frequencies were used for categorical variables. Differences between two numerical values of the characteristic groups were compared using unpaired Student's t-tests. The categorical variables were compared using $\chi^{2}$ tests. Stepwise multiple regression analysis was used to test the influence of various predictors for CVD among diabetic patients.
A $P$ value of $\leq 0.05$ was considered to be significant in two-tailed tests. Statistical analysis was performed using SPSS version 12.0.1.

\section{Results}

Table 1 shows the baseline characteristics of the study patients. Of the selected patients, $77.1 \%$ were Malays, and $57.2 \%$ were females. The mean age was 55 years. Regarding medical history, $86.9 \%$ of the patients reported with a history of hypertension; cerebrovascular accident was reported in $6.5 \%$

Table 1. Baseline characteristics and lipid profile parameters of the recorded patients, $n=245$.

\begin{tabular}{|c|c|}
\hline Characteristics & Average \\
\hline Age(years) ${ }^{a}$ & $54.9(9.7)$ \\
\hline \multicolumn{2}{|l|}{ Sex } \\
\hline Male ${ }^{b}$ & $105(42.8)$ \\
\hline Female ${ }^{b}$ & $140(57.2)$ \\
\hline Duration of diabetes (years) ${ }^{a}$ & $10(5.2)$ \\
\hline \multicolumn{2}{|l|}{ Ethnicityb } \\
\hline Malays & 189(77.1) \\
\hline Non Malays & $56(22.9)$ \\
\hline$C V D^{b}$ & 48(19.6) \\
\hline \multicolumn{2}{|l|}{ Cardiovascular risk factors ${ }^{b}$} \\
\hline Hypertension & 213(86.9) \\
\hline Family history of premature heart disease & 25(10.2) \\
\hline Age risk (men $\geq 45$ or women $\geq 55$ & 151(61.6) \\
\hline Smoking & $13(5.3)$ \\
\hline Cerebrovascular accident $^{\mathrm{b}}$ & $16(6.5)$ \\
\hline \multicolumn{2}{|l|}{ Fasting blood glucose } \\
\hline $\mathrm{mmol} / /^{\mathrm{a}}$ & $9(0.5)$ \\
\hline $\mathrm{mg} / \mathrm{dl}$ & $162.2(10)$ \\
\hline \multicolumn{2}{|l|}{ Fasting lipid profiles ${ }^{a}$} \\
\hline $\mathrm{TC} \mathrm{mmol} / \mathrm{l}$ & $6.3(1.3)$ \\
\hline LDL-C mmol// & $4.0(1.2)$ \\
\hline $\mathrm{HDL}-\mathrm{C} \mathrm{mmol} / \mathrm{l}$ & $1.3(0.6)$ \\
\hline \multirow[t]{2}{*}{$\mathrm{TG} \mathrm{mmol} / \mathrm{l}$} & $1.9(1.2)$ \\
\hline & (SD). $b: \mathrm{n}(\%)$ \\
\hline
\end{tabular}


Table 2. Characteristics of diabetic subjects with and without cardiovascular diseases.

\begin{tabular}{|c|c|c|c|}
\hline \multirow{3}{*}{ Domains/Facets } & CVD positive & CVD negative & \multirow{3}{*}{$\begin{array}{l}P \\
\text { value }\end{array}$} \\
\hline & n (\%) & n (\%) & \\
\hline & $48(19.6)$ & $197(80.4)$ & \\
\hline $\operatorname{Age}^{*,}$ a & $56.2(9.8)$ & $54.6(9.7)$ & 0.4 \\
\hline Age at risk*, b & $40(83.3)$ & $111(56.3)$ & 0.04 \\
\hline \multicolumn{4}{|l|}{$\operatorname{Sex}^{b}$} \\
\hline Male & $23(47.9)$ & $80(52.1)$ & \multirow{2}{*}{0.06} \\
\hline Female & $25(52.1)$ & $117(47.9)$ & \\
\hline \multicolumn{4}{|l|}{ Ethnicityb } \\
\hline Malays & $41(84.3)$ & $148(75.1)$ & \multirow{2}{*}{0.08} \\
\hline Non Malays & $7(14.6)$ & $49(24.8)$ & \\
\hline $\begin{array}{l}\text { Duration of } \\
\text { diabetes* }\end{array}$ & $9(6.7)$ & $4(1.9)$ & 0.03 \\
\hline Hypertension ${ }^{b}$ & 45(93.7) & $168(85.2)$ & 0.08 \\
\hline Smoking ${ }^{b}$ & $4(8.3)$ & $9(4.5)$ & 0.2 \\
\hline $\begin{array}{l}\text { Family history of } \\
\text { PCVDb }\end{array}$ & $15(31.2)$ & $10(5.10)$ & 0.03 \\
\hline \multirow{2}{*}{$\begin{array}{l}\text { Fasting blood } \\
\text { glucose level } \\
\text { mmol/l(mg/dl })^{*} \text { a }\end{array}$} & $9.3(0.6)$ & $8.1(0.3)$ & \multirow{2}{*}{0.1} \\
\hline & $167.7(7)$ & $145.9(8)$ & \\
\hline \multicolumn{4}{|c|}{ Lipid profile parameters mmol//*,a } \\
\hline $\mathrm{TC}$ & $6.4(1.2)$ & $5.9(1.3)$ & 0.02 \\
\hline TG & $1.8(1.1)$ & $2.0(1.3)$ & 0.4 \\
\hline LDL-C & $4.1(1.2)$ & $3.8(1.3)$ & 0.2 \\
\hline HDL-C & $1.1(0.6)$ & $1.5(0.3)$ & 0.01 \\
\hline \multicolumn{4}{|c|}{$\begin{array}{r}* \text { : Data are expressed as mean (SD), } \\
\text { a. Independent t-test was used, b: Chi square test was used }\end{array}$} \\
\hline
\end{tabular}

of the cases, while smoking status was recognized in $5.3 \%$. The mean LDL-C level was $4.0 \mathrm{mmol} / \mathrm{l}$ and the mean $\mathrm{HDL}-\mathrm{C}$ level was $1.3 \mathrm{mmol} / \mathrm{l}$.

Cardiovascular disease was reported in 19.6\%. The clinical characteristics of the CVD-positive and CVD-negative patients are shown in Table 2.

A significantly higher proportion of CVD patients had a higher age risk (men $\geq 45$ years; women $\geq 55$ years) compared to the non CVD group ( $P=0.04)$. Those with CVD had a significantly longer duration of diabetes than those without CVD ( $P=0.03)$. Total cholesterol was significantly higher in patients with
CVD ( $P=0.02)$, while HDL-C was significantly lower among those with CVD ( $P=0.01)$.

A stepwise multiple regression analysis was used to identify independent predictors of CVD among the 245 diabetic patients. Significant independent risk factors for CVD were family history of PCVD $(\mathrm{OR}=1.5, \mathrm{Cl} 95 \%$ : 1.1-3.6), older age $(\mathrm{OR}=1.8, \mathrm{Cl}$ 95\%: 1.0-2.1), duration of DM (OR=2.1, Cl 95\%: 0.9-2.6), basal TC level (OR=1.4, C 95\%: 1.0-1.7) and basal HDL-C level (OR =0.5, Cl 95\%: 0.2-1.0) (Table 3).

Table 3. Predictors of cardiovascular disease by multivariate analyses.

\begin{tabular}{|c|c|c|}
\hline Variables & $\begin{array}{l}\text { Adjusted OR } \\
\text { (95\% CI) }\end{array}$ & $\begin{array}{c}\text { P } \\
\text { value }\end{array}$ \\
\hline \multicolumn{3}{|l|}{ Family history of PCVD } \\
\hline No family history & $1 *$ & \multirow{2}{*}{0.03} \\
\hline Positive family history & $1.5(1.1-3.6)$ & \\
\hline \multicolumn{3}{|l|}{ Age at risk } \\
\hline Low risk group & $1 *$ & \multirow{2}{*}{0.02} \\
\hline High risk group & $1.8(1.0-2.1)$ & \\
\hline Duration of diabetes & $2.1(0.9-2.6)$ & 0.01 \\
\hline Basal TC & $1.4(1.0-1.7)$ & 0.03 \\
\hline \multirow[t]{2}{*}{ HDL-C } & $0.5(0.2-1.0)$ & 0.001 \\
\hline & \multicolumn{2}{|c|}{ *: Reference group } \\
\hline
\end{tabular}

\section{Discussion}

Diabetes mellitus is one of the most common diseases that can cause a significant morbidity and mortality. It is a serious incapacitating and lethal condition that has now shows an increasing proportions globally. [5]

It was reported that CVD is present about 2- to 3-times more among both type 1 and type 2 diabetic patients in contrast to the age- and gender matched non-diabetic persons. Cardiovascular diseases are responsible for the majority of hospital admissions for diabetic subjects; it accounts a very high cost that maybe expended on the health care system among that population. Because of such 
enormous financial and social costs, more attention must be focused on the CVD crisis among diabetic subjects. [17]

In this study we studied a group of Malaysian diabetics who attended HUSM, trying to recognize their clinical problems and their predictors of CVD.

The mean age of the diabetic patients was 54 years. The diabetic patients were older in this study compared to other study done among Malaysian diabetic patients. [18] This may be explained by the improvement in the life circumstances and the better socioeconomic status.

In this study CVD was found to be present in about $20 \%$ of the studied population which is less than that reported among other diabetic groups (38\%) and (25\%) [19,20]. This can be explained by the difference in the lifestyle for each population also the difference in the criteria for diagnosing CVD among the study population and other methodological techniques. The genetic variations among different population can contribute to the variation in the incidence of CVD.

The high prevalence of cardiovascular risk factors coupled with the unhealthy lifestyle practices may account for the early development of CVD, which has increased rapidly in Malaysia to become the major cause of morbidity and mortality in the country. [21]

In this study, those with CVD show a highly significant TC and lower LDL-C levels than those without CVD. This finding was in agreement with other study done among type 2 DM. [22]

In this study TC level was detected as a predictor of CVD among diabetic patients which was in union with a similar research. [22] Also TC level was a predictor for CVD among Malaysian dyslipidemic patients. [23]

High density lipoprotein cholesterol value was recognized as a predictor for CVD which was in agreement with other study done among Spanish diabetic patients. [22]

Hypercholesterolemia plays an important pathological role in the cardiovascular risk associated with diabetics. [24] However, there are other lipid abnormalities that are more characteristic of diabetes, such as high triglyceride level and HDL-C deficiency. It is also not clearly identified which of these lipid abnormalities is the best predictor for cardiovascular risk among diabetes. [25]

Data were obtained from the Multiple Risk Factor Intervention Trial (MRFIT) showed a three times increased in the CVD death among diabetic men. Furthermore, serum cholesterol level, systolic blood pressure, and smoking status were predictors of CVD mortality among those diabetic men. [26]

Evidence for the benefits of lipid-lowering therapy in patients with DM was demonstrated in multiple clinical trials, and it is well acknowledged that patients with DM have an increased prevalence of lipid abnormalities that can contribute to their high risk of CVD.

In the present study duration of diabetes was a significant predictor for CVD among diabetic patients.

The importance for the early identification of diabetes was supported by recent data from a screening model program, which highlighted about the cost-effectiveness of the early prediction and diagnosis of diabetes. [27] The Framingham Heart Study, have shown that diabetes duration is an important risk factor for CVD mortality. [28]

Overall, the results of this study suggest the need to early identify and treat dyslipidemia together with the other the risk factors that may play an important role in the development of atherothrombosis and CVD among diabetic patients.

Data from hospital records are vital resource of information for epidemiological studies. Such studies can help to identify the common and important health problems in the community and provide assumptions for the future work. Moreover, claims information, in a combination with other data such as laboratory data, administrative and clinical data can provide a more powerful tool for understanding the real- impacts of early diagnosis and treatment on the patients health. [ 29] 
However, retrospective hospital database analysis is subjected to certain problems, including limitations that can be caused by selectivity, misdiagnosis, improper data coding, and plus admissions policies. The problem of selectivity was reduced in the current study, because the sample included both inpatients and outpatients and included both types of diabetes. The current data were collected from a single centre (HUSM) that may therefore not be representative of the whole Malaysian community; it may, however, represent the northeast Malaysian population, as the selected hospital concerned is regarded as a referral center for many other states in the northeast region. [23] A further potential limitation was that patient compliance, the level of physical activity and the dietary habits of the patients could not be investigated.

\section{Conclusions}

The predictors of CVD among Malaysian diabetic patients are duration of diabetes, TC, HDL-C levels, family history of PCVD and age risk.

\section{Acknowledgements}

We would like to acknowledge the Record Unit of Universiti Sains Malaysia for their assistance in the development of this article.

\section{Conflict of interest}

The authors declare no conflicts of interest.

\section{References}

1. International Diabetes Federation. IDF Diabetes Atlas fourth edition. From http://www.idf.org/diabetesatlas/. Accessed: August 2012

2. Gonzalez E, Johansson S, Wallander M, Rodriguez L. Trends in the prevalence and incidence of diabetes in the UK:1996-2005. J Epidemiol Community Health. 2009; 63(10): 332-36.

3. Bener A, Zirie M, Al-Hamaq A, Musallam M. Prevalence of diagnosed and undiagnosed diabetes mellitus and its risk factors in a population-based study of Qatar. Diabetes Res Clin Pract. 2009; 84(1):99-106.

4. Mafauzy M. Diabetes Mellitus in Malaysia. Med J Malaysia. 2006; 61(4):397-98.

5. Ministry of Health Malaysia. Public Health Institute. Report of the Second National Health and Morbidity Survey Conference Kuala Lumpur. 20-22 November 1997.

6. Williams R, Gaal LV, Lucioni C. Assessing the impact of complications on the costs of Type II diabetes. Diabetologia. 2002; 45(7): 13-7.

7. National Cardiovascular Disease Database (NCVD) Malaysia. 9th Annual Meeting. 2015. http://www.acrm.org.my/ncvd/.

8. Singh RB, Rastogi SS, Rastogi V, Niaz MA, Madhu SV, Chen M, Shoumin Z. Blood pressure trends, plasma insulin levels and risk factors in rural and urban elderly populations of north India. Coron Artery Dis. 1997; 8(7): 463-68.

9. Chen Z, Peto R, Collins R, MacMahon S, Lu J, Li W. Serum cholesterol concentration and coronary heart disease in population with low cholesterol concentrations. BMJ. 1991; 303 (6797): 276-82.

10. Grundy SM, Cleeman JI, Merz CN, et al . Implications of recent clinical trials for the National Cholesterol Education Program Adult Treatment Panel III guidelines. Circulation. 2004; 110(2): 227-39

11. Bosch X, Alfonso F, Bermejo J. Diabetes and Cardiovascular Disease. A Comprehensive Insight to the New Epidemic of the 21st Century. Rev Esp Cardiol. 2002; 55(5):525-7.

12. Almdal T, Scharling $H$, Jensen JS, Vestergaard $H$. The independent effect of type 2 diabetes mellitus on ischaemic heart disease, stroke, and death. A population-based study of 13000 men and women with 20 years of follow-up. Arch Int Med. 2004; 164(13):1422-26.

13. American Diabetes Association. Standards of medical care in diabetes. Diabetes Care. 2016; 39 (suppl 1): 1-112.

14. World Health Organization. International Society of Hypertension Guidelines for the Management of Hypertension. Guidelines Subcommittee. J Hypertens. 1999; 17(2): 151-183. 
15. Scheuner MT, Whitworth WC, McGruder H, Yoon PW, Khoury MJ. Expanding the definition of a positive family history for early-onset coronary heart disease. Genet Med. 2006; 8: 491501.

16. NCEP. Executive Summary of The Third Report of The National Cholesterol Education Program (NCEP) Expert Panel on Detection, Evaluation, And Treatment of High Blood Cholesterol In Adults (Adult Treatment Panel III). JAMA. 2001;285: 2486-97.

17. Jennifer $B$, Philip Raskinb. Cardiovascular risk in diabetes. $A$ brief review. Journal of Diabetes and Its Complications. 2000; 14 : 108-15

18. Syed Azhar SS, Daud M. Ishaq A, Ali JM, Abdul RM, Mohamed A, Moussa A. Role of Diabetes in the Prognosis and Therapeutic Outcome of Tuberculosis. International Journal of Endocrinology. 2012; 645: 362- 6

19. Prescott A., J.E. Bailey, K.J. Kelly, T. Munyombwe, A. Gray, L.K.M.. The effectiveness and cost of single and multi-factorial cardiovascular risk factor modification to guideline targets in type 2 diabetes. Prim Care Diabetes. 2012; 6:67-73.

20. Peter H. Winocour, Paul N. Durringtona, b et al. A cross-sectional evaluation of cardiovascular risk factors in coronary heart disease associated with Type 1 (insulin-dependent) diabetes mellitus. Diabetes Research and Clinical Practice. 1992; 18:17384.

21. Liew YM, Zulkifli A, Tan H, Ho YN, Khoo KL. Health status of senior civil servants in Kuala Lumpur. Med J Malaysia. 1997; 52: 348-66.

22. Xavier P, Emili C, Rosaura F, et al .On behalf of the ESODIAH study group. Factors Predictive of Cardiovascular Disease in Patients with Type-2 Diabetes and Hypercholesterolemia. ESODIAH Study. Rev Esp Cardiol. 2007; 60:251-58

23. Alyaa A, Mohd SM, Kamarul I, Suhairi I, Bin Alwi Z, Zurkurnai Y. Lipid Profile Parameters in Malaysian Dyslipidemic Patients. Kobe J. Med. Sci 2011; 57: 38-48.

24. Selvin E, Marinopoulos S, Berkenblit G et al. Meta-analysis: glycosylated hemoglobin and cardiovascular disease in diabetes mellitus. Ann Intern Med. 2004; 141:421-31.

25. Austin MA, King M-C, Vranizian KM, Krauss RM. Atherogenic lipoprotein phenotype: a proposed genetic marker for coronary heart disease risk. Circulation. 1990; 82 :495-06.

26. Stamler, J. H., Vaccaro, O., Neaton, J. D., \& Wentworth, D. Multiple Risk Factor Intervention Trial Research Group. Diabetes screened in the Multiple Risk Factor Intervention Trial. Diabetes Care. 1993; $16: 434-44$.
27. Kahn $R$, Alperin $P$, Eddy $D$, et al:. Age at initiation and frequency of screening to detect type 2 diabetes: a cost-effectiveness analysis. Lancet. 2010; 375:1365-74.

28. Fox CS, Sullivan L, D'Agostino RB Sr, et al. The significant effect of diabetes duration on coronary heart disease mortality: the Framingham Heart Study. Diabetes Care. 2004; 27:704-8.

29. Bullano MF, Wertz DA, Yang GW, et al. Effect of rosuvastatin compared with other statins on lipid levels and National Cholesterol Education Program goal attainment for low-density lipoprotein cholesterol in a usual care setting. Pharmacotherapy. 2006; 26: 469-78.
Publish in International Archives of Medicine

International Archives of Medicine is an open access journal publishing articles encompassing all aspects of medical science and clinical practice. IAM is considered a megajournal with independent sections on all areas of medicine. IAM is a really international journal with authors and board members from all around the world. The journal is widely indexed and classified Q1 in category Medicine. 